\title{
Assessment of Dimensionless Form of Kostiakov Model
}

\author{
Mohammad Zakwan ${ }^{1 *}$ \\ ${ }^{1}$ Research Scholar, Department of Civil Engineering, IIT Roorkee, Roorkee, India 247667
}

*Corresponding Author: zakwancivil@gmail.com

Citation: Zakwan, M. (2017). Assessment of Dimensionless Form of Kostiakov Model. Aquademia: Water, Environment and Technology, 1(1), 01.

doi: 10.20897 /awet.201701

Published: June 30, 2017

\begin{abstract}
Infiltration is the process by which water enters the earth's surface. Although contribution of soil water to total water present on earth surface is negligible, but it is of prime importance for plant life. Very recently, dimensionless form of Kostiakov equation was proposed for precise estimation of Kostiakov model parameters. The present paper is an assessment of accuracy of proposed dimensionless form of Kostiakov model. However, it has been found that the cumulative infiltration estimated by nonlinear optimization technique are more accurate than those estimated by dimensionless form of Kostiakov equation and the graphical method. Therefore, the present paper proposes application of Generalized Reduced Gradient (GRG), a nonlinear optimization technique to estimate Kostiakov model parameters precisely rather than using dimensionless form of Kostiakov equation. Infiltration data of various types of soil have been considered in the present study for the generalization of the results.
\end{abstract}

Keywords: dimensionless, infiltration, Kostiakov model, parameter, precise

\section{INTRODUCTION}

Infiltration is defined as the process by which water enters the earth's surface. Estimation of infiltration rate plays a vital role in efficient design and operation of surface irrigation systems. Further, determination of infiltration characteristics of soil is helpful in estimation of surface runoff, hydrograph analysis, groundwater recharge and crop water requirement. Infiltration characteristics of a soil is influenced by a host of factors which include surface cover condition of soil, rainfall characteristics, soil properties, soil condition and climatic conditions. Taking these factors into account various physical, empirical and semi empirical infiltration models have been proposed by researchers over the years. Physically based models are approximate solution of Richard's equation such as GreenAmpt model (1911) and Smith model (1972). Semi empirical models may be viewed as a compromise between physical and empirical models. Semi empirical models are based on continuity equation and flux concentration relations such as Horton model (1938), Overton (1964) and Singh and Yu model (1990). Empirical models are derived based on field and experimental data such as Huggins and Monke model (1966) and Collis-George model (1977).

Although several comparative analyses were carried out to assess the suitability of infiltration models under varying field conditions, but, there was little emphasis on the technique used to estimate the infiltration model parameter which plays a vital role in assessment of infiltration model performance. As far as the conventional graphical method is concerned it can estimate the parameters of infiltration models which involve linear equations accurately such as Green-Ampt model, but its application introduces inaccuracy in parameter estimation of models which require log transformation for application of linear regression as already proved in many other applications (Ferguson (1986)). Rawls (1983) emphasized on development of procedures for estimating infiltration model 
parameters. Application of pedotransfer functions to determine soil characteristics was introduced by Wosten et al (2001). Mishra et al. (2003) applied BFGS technique for estimating parameters of fourteen infiltration models. Deep and Das (2008) used various optimization techniques to estimate infiltration model parameters that included Software Language of Interactive General Optimization (LINGO), Binary Genetic algorithm (BGA), Random Search Technique (RST), Hybrid Binary Genetic Algorithm (HBGA), Real coded Genetic Algorithm using Laplace crossover and Power Mutation (LX-PM), and its hybrid version (H-LX-PM) thereby reporting HBGA as best suited optimization technique for estimation of infiltration rates. Haghighi et al (2010) used MATLAB for estimation of final infiltration and sorptivity factor for Taleghan watershed in Iran and concluded that use of pedotransfer functions (PTFs) is limited to specific similar sites for which they are calibrated. GENSTAT a statistical software was employed by Ogbe et al (2011) to fit infiltration equations to Nigerian soils. Haghiabi et al (2011) transformed Kostiakov and modified Kostiakov model into dimensionless form for more accurate parameter estimation as compared to conventional graphical method. Chen et al (2015) demonstrated the existence of optimal parameters for Green-Ampt model, but these parameters had considerable deviations for shorter rainfall durations.

\section{MATERIALS AND METHOD}

In the present study infiltration data sets have been collected from various sources. The data sets comprise of infiltration data for sandy loam of South East Nigeria (Uloma et al. (2014)), sandy soil of North central Nigeria (Ogbe et al. (2011)), clay and black cotton soil of India (Dagadu and Nimbalkar (2012)). Field experiments were carried out using double ring infiltrometer in all the cases. Kostiakov infiltration model is one of the most commonly used infiltration model because of its flexibility to fit most of the observed infiltration data. Details of Kostiakov model are as follows.

\section{Kostiakov Mode1}

Kostiakov (1932) proposed an empirical model for estimation of cumulative infiltration capacity (F). Cumulative infiltration capacity in Kostiakov model may be presented as

$F=a t^{b}$

The cumulative infiltration capacity can be related to infiltration capacity ( $f$ ) at any time $t$ as

$f=\frac{d F(t)}{d t}$

By differentiating equation (2) the infiltration rate can be expressed as

$f=(a b) t^{b-1}$

where $\mathrm{a}$ and $\mathrm{b}$ are constants such that $\mathrm{a}>0$ and $0<\mathrm{b}<1$.

Equation (2) and (3) are applicable for $\mathrm{t} \neq 0$.

In the conventional graphical method, the parameters in the Kostiakov model are estimated by fitting a straight line to an arithmetical plot of $\ln (\mathrm{F})$ against $\ln (\mathrm{t})$. The intercept of the best fit straight line on the ordinate axis will then represent the value of $\ln (a)$ and its slope will be equal to $b$.

\section{Dimensionless form of Kostiakov model}

Haghiabi et al. (2011) proposed the dimensionless form of Kostiakov model for precise estimation of model parameters which may be expressed as

$$
\begin{aligned}
& \mathrm{F}^{*}=\mathrm{t}^{* \mathrm{~b}} \\
& \text { Where } \\
& \mathrm{F}^{*}=\frac{\mathrm{F}}{\mathrm{F}_{\mathrm{e}}} \\
& \mathrm{t}^{*}=\frac{\mathrm{t}}{\mathrm{t}_{\mathrm{e}}} \\
& \mathrm{F}^{*}=\frac{\mathrm{F}_{\mathrm{e}}}{\mathrm{t}_{\mathrm{e}}^{\mathrm{b}}} \mathrm{t}^{* \mathrm{~b}}
\end{aligned}
$$

in which $t_{e}$ is the total time elapsed from start till the end of the test and $F_{e}$ is the cumulative infiltration at the end of test.

In this paper equation (1) is referred to as standard form of Kostiakov equation while equation (7) is referred to as dimensionless form of Kostiakov equation. The parameters of the standard form of Kostiakov equation were estimated by using conventional graphical method as described earlier as well as GRG technique. To estimate the parameters using GRG technique sum of square of error between observed cumulative infiltration and estimated cumulative infiltration (equation (1)) was set to minimization. Similarly, the parameters in dimensionless form of Kostiakov equation were estimated by minimizing sum of square of error between observed cumulative infiltration and estimated cumulative infiltration (equation (7)) using GRG technique. 


\section{GRG Optimization technique}

GRG is an optimization tool implanted in Microsoft excel which is capable of optimizing complex nonlinear programming problems. In this optimization tool two techniques are available for determination of search direction. The default choice is Quasi-Newton method and the second choice is the Conjugate Gradient method. Quasi-Newton method requires more storage space for storage of Hessian matrix. Depending on the available storage GRG can automatically switch between the Quasi-Newton or Conjugate Gradient method.

Application of spreadsheet based optimization technique has gained popularity in the field of water resource engineering over the years. Bhattacharjya (2010) applied excel solver for estimation of critical depth in open channel flow problems. Barati (2013) applied spreadsheet based optimization technique to obtain optimal parameters of nonlinear Muskingum flood routing equation. Che et al. (2014) demonstrated that GRG technique is an efficient means for determination of optimal unit hydrograph of watersheds. Discharge rating curve at a gauging site was established by using GRG technique by Muzzamil et al. (2015). Intensity Duration Frequency curve parameters were estimated using GRG technique by Zakwan (2016). Zakwan and Muzzammil (2016) applied GRG solver for flood routing.

\section{RESULTS AND DISCUSSION}

In the present paper, five data sets of cumulative infiltration were used to assess the efficiency of dimensionless form Kostiakov infiltration model to fit the observed data. The model parameter of dimensionless Kostiakov model (Haghiabi method) were estimated using GRG technique and the parameters of standard Kostiakov equation were estimated using the graphical method as well as nonlinear optimization GRG technique as shown in Table 1. The cumulative infiltration rates were then calculated using equation (1) and equation (7).

Table 1. Performance indices for comparative analysis of the two approaches.

\begin{tabular}{|c|c|c|c|c|c|c|c|}
\hline \multirow{2}{*}{ Data set } & \multirow{2}{*}{ Soil Type } & \multirow{2}{*}{ Method } & \multicolumn{2}{|c|}{ Parameters } & \multicolumn{3}{|c|}{ Performance indices } \\
\cline { 3 - 8 } & & $\mathbf{a}$ & $\mathbf{b}$ & SSE & \multicolumn{2}{|c|}{ R } & IA \\
\hline \multirow{3}{*}{1} & \multirow{3}{*}{ Sandy loam } & Optimization & 9.69 & 0.56 & 0.07 & 0.99 & 0.99 \\
& & Haghiabi & 9.69 & 0.56 & 0.07 & 0.99 & 0.99 \\
& & Graphical & 9.69 & 0.58 & 0.26 & 0.99 & 0.98 \\
\hline \multirow{3}{*}{2} & \multirow{3}{*}{ Sandy loam } & Optimization & 22.33 & 0.61 & 17.21 & 0.99 & 0.96 \\
& & Haghiabi & 22.17 & 0.59 & 22.19 & 0.99 & 0.95 \\
& & Graphical & 22.07 & 0.70 & 52.03 & 0.99 & 0.94 \\
\hline \multirow{3}{*}{3} & \multirow{3}{*}{ Sandy } & Optimization & 34.63 & 0.73 & 2.97 & 0.99 & 0.98 \\
& & Haghiabi & 34.61 & 0.73 & 3.12 & 0.99 & 0.98 \\
& \multirow{3}{*}{4} & Graphical & 34.51 & 0.79 & 30.70 & 0.99 & 0.97 \\
\hline \multirow{3}{*}{5} & \multirow{3}{*}{ Ploughed clay } & Optimization & 3.25 & 0.47 & 0.06 & 0.99 & 0.94 \\
& & Haghiabi & 3.20 & 0.46 & 0.07 & 0.99 & 0.94 \\
& \multirow{3}{*}{ Black cotton } & Graphical & 3.38 & 0.53 & 0.11 & 0.98 & 0.91 \\
\hline & & Optimization & 2.61 & 0.64 & 0.09 & 0.99 & 0.98 \\
& & Haghiabi & 2.56 & 0.61 & 0.12 & 0.99 & 0.97 \\
& & Graphical & 2.66 & 0.73 & 0.23 & 0.99 & 0.96 \\
\hline
\end{tabular}

It has been observed that using the three approaches Kostiakov model parameters obtained are different. Specially, in case of graphical method the parameters obtained are quite different from those obtained by other two approaches. This difference may be attributed to the fact that in conventional graphical method the log transformed data is fitted with best fit straight rather than fitting the observed data with the best fit curve as in case of other two approaches. As a result of this difference cumulative infiltration estimated by the three approaches are different. Therefore, to assess the efficiency of these approaches following performance indices were used

Sum of Square of Error $(\mathrm{SSE})=\sum_{i=1}^{N}\left[\mathrm{~F}_{\mathrm{obs}_{\mathrm{i}}}-\mathrm{F}_{\mathrm{est}_{\mathrm{i}}}\right]^{2}$

Modified Index of Agreement $(\mathrm{IA})=\left[1-\frac{\sum_{\mathrm{i}=1}^{\mathrm{N}}\left|\mathrm{F}_{\mathrm{obs}_{\mathrm{i}}}-\mathrm{F}_{\mathrm{est}_{\mathrm{i}}}\right|}{\sum_{\mathrm{i}=1}^{\mathrm{N}}\left|\mathrm{F}_{\mathrm{obs}_{\mathrm{i}}}-\overline{\mathrm{F}}\right|+\left|\mathrm{F}_{\mathrm{est}_{\mathrm{i}}}-\overline{\mathrm{F}}\right|}\right]$

Where $F_{\text {obs }}$ is the observed cumulative infiltration, $F_{\text {est }}$ is the estimated cumulative infiltration and $\bar{F}$ is the average cumulative infiltration. Apart sum of square of error and modified index of agreement correlation coefficient (r) was also used as a performance index. Lower values of sum of square of error and higher values of index of agreement and correlation coefficient would represent the best approach for fitting the infiltration data. 

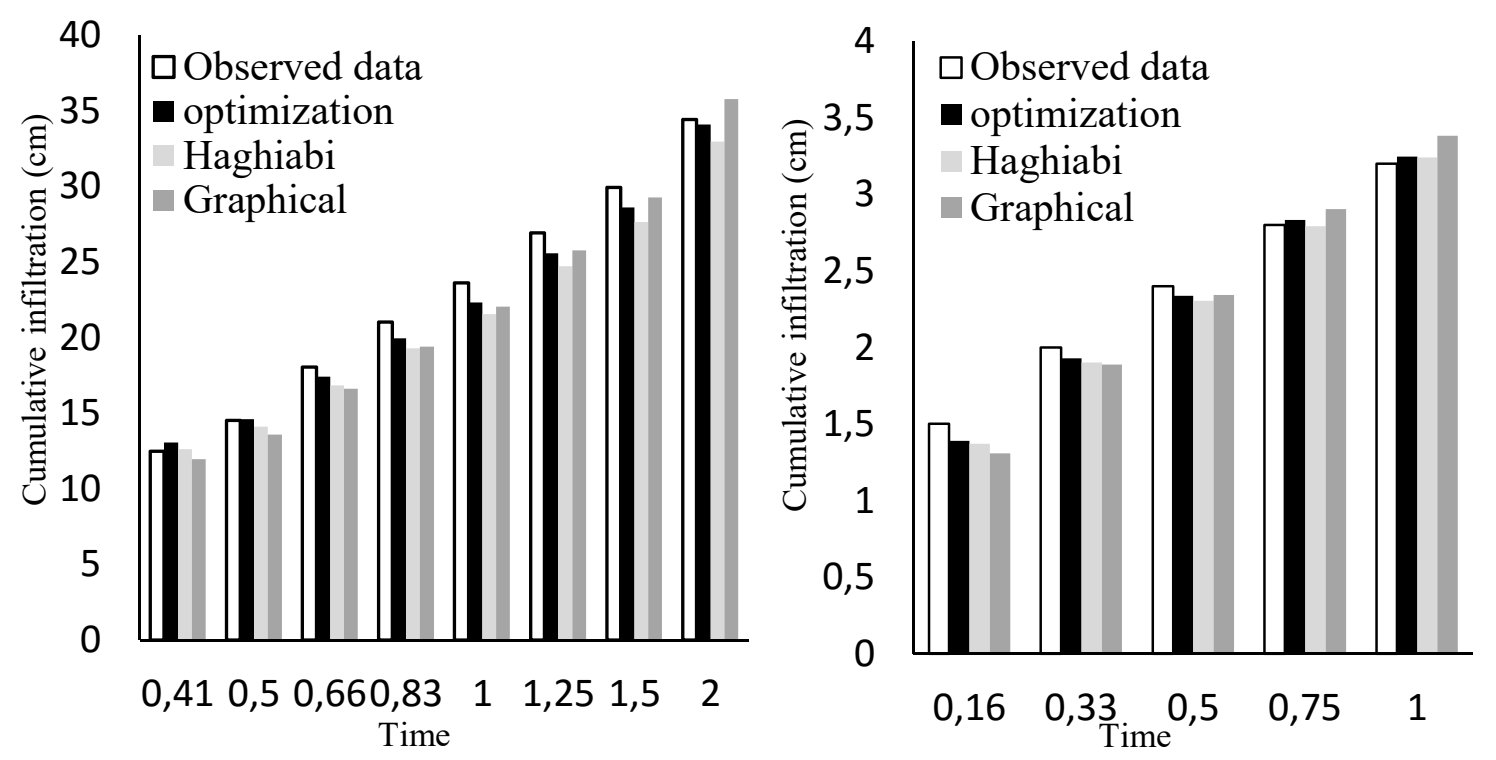

Figure 1. Comparison of cumulative infiltration obtained by different method for data set 2 and data set 4 s.

The results of comparative analysis along with estimated parameters are presented in Table 1. Analysis of Table 1 clearly shows that in almost all the cases application of nonlinear optimization approach results in highest fitness efficiencies and lowest error. Further, the application of conventional graphical approach results in lowest fitness efficiencies and highest error. Qualitative of the results typical of which are shown in Figure 1 too justify the fact that the cumulative infiltration obtained at various time step by optimization approach are most concurrent with observed data followed by Haghiabi approach and graphical approach. Column charts were used in qualitative analysis to present a clear comparative analysis of the three approaches with respect to the observed data.

Therefore, based on the above quantitative and qualitative analysis it can be said that although, the claims of Haghiabi et al. (2011) that dimensionless form of Kostiakov equation proposed by them are superior to graphical method for predicting cumulative infiltration but less accurate estimation of cumulative infiltration when compared to cumulative infiltration estimated by application of nonlinear optimization technique. Therefore, the problem of inaccurate estimation of cumulative infiltration by $\log$ transformed of Kostiakov equation could be better handled by application of nonlinear optimization technique rather than the application of the proposed dimensionless form of Kostiakov equation. Accurate determination of infiltration characteristics of soil is a prime requirement for reliable estimation of surface runoff, hydrograph analysis, groundwater recharge and crop water requirement.

\section{CONCLUSION}

Cumulative infiltration was estimated using standard and dimensionless form of Kostiakov model for five data sets that contained clay soil, black cotton soil, sandy loam (two data sets) and sandy soils. Qualitative analysis of the results reveals that the application of nonlinear optimization technique to estimate parameters of standard form of Kostiakov model result in more accurate estimation of cumulative infiltration rather than the proposed dimensionless form of Kostiakov model (Haghiabi et al. (2011)). The use of highly simplified spreadsheet based optimization technique eliminates the need of time consuming graphical method of curve fitting. Further, GRG technique is spreadsheet based optimization technique and does not require any programming expertise or complex parameter tuning can gain popularity among agricultural bodies disseminating infiltration data because of its simplicity and reliability in estimating infiltration model parameters.

\section{REFERENCES}

Barati, R. Application of excel solver for parameter estimation of the nonlinear Muskingum models. KSCE J. Civ. Eng., 2013, 17(5), 1139-1148.

Bhattacharjya, R. K. Discussion of Evolutionary algorithm for the determination of critical depths in conduits. J. Irrig. Drain. Eng., 2010, 10.1061/ (ASCE) 0733-9496(2008)134:6(847) 847-852.

Che, D.; Nangare, M. and Mays, L. W. Determination of Optimal Unit Hydrographs and Green-Ampt Parameters for Watersheds. J. Hydrol. Eng., 2014, 19(2), 375-383. 
Chen, L.; Xiang, L.; Young, M.H.; Yin, J.; Yu, Z. and Genuchten, M.T.V. Optimal parameters for the Green-Ampt infiltration model under rainfall condition. J. Hyd. Hydromech., 2015, 63(2), 93-101.

Collis-George N. Infiltration equations for simple soil systems. Water Resources Research, 1977, 13(2), 395- 403.

Dagadu, J.S. and Nimbalkar, P.T. Infiltration studies of different soils under different soil conditions and comparison of infiltration models with field data. IJAET, 2012, 3(2), 154-157.

Deep, K. and Das, K.N. Optimization of Infiltration parameters in hydrology. W. J. Mod. Sim. 2008, 4(2), 120130.

Ferguson, R. I. River loads underestimated by rating curves. Water Resour. Res.1986, 22(1), 74-76.

Green W. H, Ampt C. A. Studies on soil physics, I. Flow of air and water through soils. Journal of Agricultural Science, 1911, 4, 1- 24.

Haghiabi, A.; Abedi-koupai, J; Heidarpour, $M$ and Mohammadzadeh-habili, J. A new method for estimating parameters of Kostiakov and Modified Kostiakov infiltration equations. World Appl. Sci. J., 2011, 15(1), 129135.

Haghighi, F.; Gorji, M; Shorafa, M; Sarmadian, F and Mohammadi, M.H. Evaluation of some infiltration models and Hydraulic parameters. Span. J. of Agr. Res., 2010, 8(1), 211-217.

Horton, R. I. The interpretation and application of runoff plot experiments with reference to soil erosion problems. Soil Science Society of America Proceedings, 1938, 3, 340- 349.

Huggins LF, Monke EJ. The mathematical simulation of the hydrology of small watersheds. Technical Report No. 1, Purdue Water Resources Research Centre, Lafayette, 1966.

Mishra, S. K., Tyagi, J. V. and Singh, V. P. Comparison of infiltration models. Hydrol. Proc., 2003, 17, 2629-2652.

Muzzammil, M., Alam, J. and Zakwan, M. An optimization technique for estimation of rating curve parameters. Nat. Symp. Hydrol. New Delbi, 2015, 234-240.

Ogbe, V.B.; Jayeoba, O.J. and Ode, S.O. Comparison of four soil infiltration models on a sandy soil in Lafia, southern Guinea Savanna zone of Nigeria. PAT, 2011, 7(2), 116-126.

Overton DE. Mathematical refinement of an infiltration equation for watershed engineering, U.S. Department of Agricultural Service, Washington, DC, 1964, 41- 99.

Rawls, W. J., Brakensiek, D.L., Miller N. Green-Ampt infiltration parameters from soils data. J. Hydraul. Eng., 1983, 109(1), 62- 70 .

Singh V. P., Yu F.X. Derivation of infiltration equation using systems approach. Journal of Irrigation and Drainage Engineering, 1990, 116(6), 837-857.

Smith R. E. The infiltration envelope: results from a theoretical infiltrometer. Journal of Hydrology, 1972, 17, 1- 21.

Uloma, A.R.; Samuel, A.C. and Kingsley, I.K. Estimation of Kostiakov infiltration model Parameters of some sandy loam soils of Ikwuano - Umuahia, Nigeria. Open Trans. Geosci., 2014, 1(1), 34-38.

Wosten, J.H.M., Pachepsky, Y.A., and Rawls, W.J. Pedotransfer functions: Bridging the gap between available basic soil data and missing soil hydraulic characteristics. J. Hydrol., 2001, 251, 123-150.

Zakwan, M. and Muzzammil, M. "Optimization Approach for Hydrologic Channel Routing". Water Ener. Inter., 2016, 59(3), 66-69.

Zakwan, M. "Application of optimization technique to estimate IDF parameters". Water Ener. Inter., 2016, 59(5), 69-71. 